\title{
Stenting of the ductus arteriosus and banding of the pulmonary arteries: basis for various surgical strategies in newborns with multiple left heart obstructive lesions
}

\author{
I Michel-Behnke, H Akintuerk, I Marquardt, M Mueller, J Thul, J Bauer, K J Hagel, \\ J Kreuder, P Vogt, D Schranz
}

Heart 2003;89:645-650

See end of article for authors' affiliations

\section{Correspondence to:}

Dr I Michel-Behnke,

Paediatric Heart Centre,

Justus-Liebig University

Feulgenstraße 12, 35385

Giessen, Germany;

Ina.Michel-Behnke.@

paediat.med.uni-giessen.de

Accepted

14 January 2003

\begin{abstract}
Objective: To present an institutional experience with stent placement in the arterial duct combined with bilateral banding of the pulmonary artery branches as a basis for various surgical strategies in newborns with hypoplastic left heart obstructive lesions.

Design: Observational study.

Setting: Paediatric heart centre in a university hospital.

Patients: 20 newborns with various forms of left heart obstructive lesions and duct dependent systemic blood flow.

Interventions: Patients underwent percutaneous ductal stenting and surgical bilateral pulmonary artery banding. Atrial septotomy by balloon dilatation was performed as required, in one premature baby by the transhepatic approach.

Main outcome measures: Survival; numbers of and reasons for palliative and corrective cardiac surgery.

Results: One patient died immediately after percutaneous ductal stenting. One patient died in connection with the surgical approach of bilateral pulmonary banding. Stent and ductal patency were achieved for up to 331 days. Two patients underwent heart transplantation and two patients died on the waiting list. Ten patients had a palliative one stage procedure with reconstruction of the aortic arch and bidirectional cavopulmonary connection at the age of 3.5-6 months. There was one death. One patient is still awaiting this approach. Two patients received biventricular repair. In one, biventricular repair will soon be provided.

Conclusions: Stenting the arterial duct combined with bilateral pulmonary artery banding in newborns with hypoplastic left heart or multiple left heart obstructive lesions allows a broad variation of surgical strategies depending on morphological findings, postnatal clinical conditions, and potential ventricular growth.
\end{abstract}

T he management of newborns with multiple left heart hypoplastic or obstructive lesions is complex. A broad morphological spectrum can be observed, ranging from mild lesions that do not require any intervention to severely obstructive or hypoplastic left heart anatomy necessitating single ventricle palliation or heart transplantation. Decisions regarding surgical management have to be made mostly in the newborn period. Moreover, the surgical strategy is rarely reversible. The outcome of patients planned for heart transplantation depends primarily on the availability of a donor heart. In our institution the mean waiting time for a donor heart for infants is $\mathbf{5 3}$ days; therefore, many patients die while waiting for an organ. ${ }^{1}$

The outcome of the Norwood procedure is influenced mainly by a successful first stage operation ${ }^{23}$; however, a significant number of patients die before the second stage of the Norwood procedure can be performed. ${ }^{24}$ Stenting the arterial duct in combination with pulmonary artery banding and, if necessary, atrial septotomy offers a new approach to palliation of hypoplastic left heart. ${ }^{5}$ Neoaortic reconstruction and establishment of a bidirectional cavopulmonary connection (BCPC) can then be performed during a single operation, as we have described recently. ${ }^{6}$ However, in selected hypoplastic left ventricles, in which left ventricular growth can be observed foremost during the postnatal follow up, the surgical decision made immediately after birth would result in a single ventricle palliation, although in the same patient biventricular repair may have been provided a few months later. ${ }^{7}$ In this context, despite multiple left heart hypoplastic or obstructive lesions, a biventricular repair is thought to be preferable when possible. ${ }^{8}$

The present study shows in a series of patients that ductal stenting and bilateral pulmonary banding allowed an extended surgical strategy in infants with multiple left heart obstructive or hypoplastic lesions depending on ventricular growth and function.

\section{METHODS \\ Patients}

Between May 1998 and March 2002, 20 newborns with a birth weight ranging from $1.6-3.7 \mathrm{~kg}$ were studied. Sixteen had typical hypoplastic left heart. One of these had a residual antegrade blood flow through a moderate hypoplastic aortic valve annulus with a diameter of $4 \mathrm{~mm}$, associated with mild mitral valve hypoplasia. Two patients had aortic valve atresia with severe hypoplasia of the aortic arch, one of them with corrected transposition, and double inlet left ventricle. Two patients had interrupted aortic arch with moderate to large ventricular septal defects and hypoplastic aortic valve annulus $(<4.5 \mathrm{~mm})$, and in one with bicommissural aortic valve (table 1). Non-cardiac diagnoses were renal tumour in one and CATCH 22 syndrome (cardiac defects, abnormal facial features, thymic hypoplasia, cleft palate, and hypocalcaemia) in another premature infant. Diagnoses were unknown 


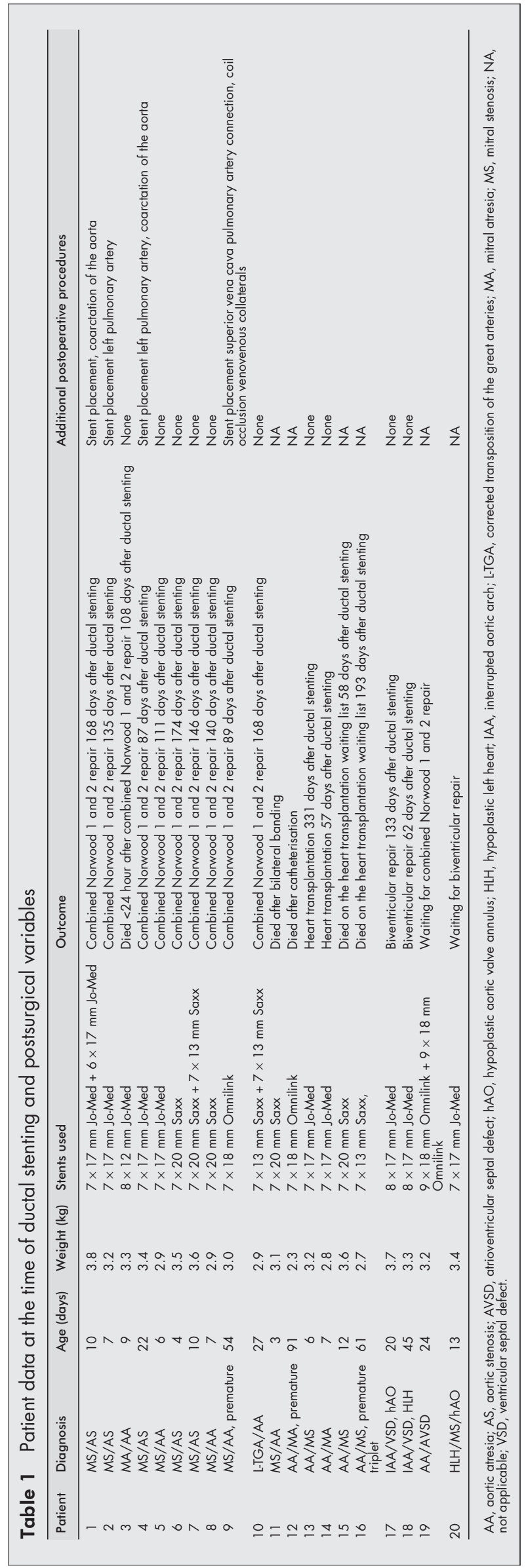

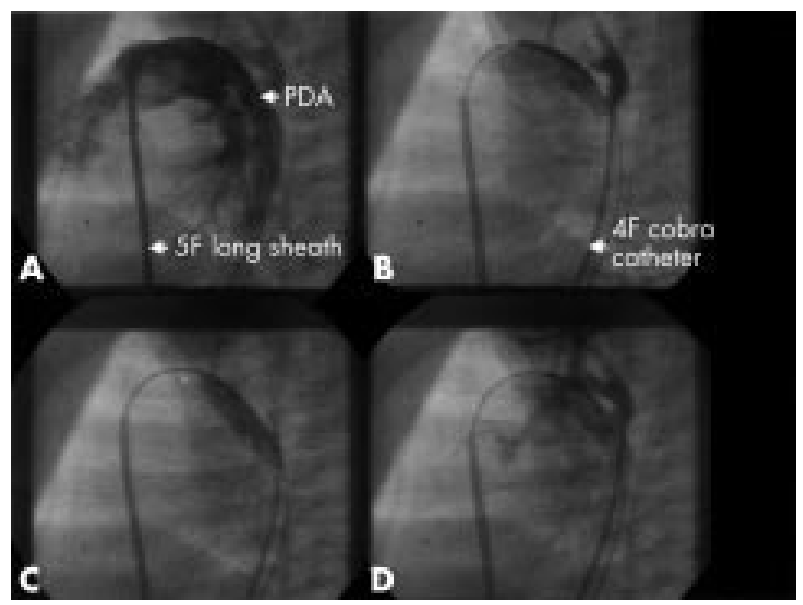

Figure 1 Ductal stenting in patient 9 (lateral view fluoroscopy). (A) Feature of the patent ductus arteriosus (DA) for measurement of ductal dimensions. Angiography is performed through the long sheath. (B) Location of the balloon stent unit not yet exactly positioned within the DA. (C) Angiography by the aortic 4 French cobra catheter. Inflated balloon with a fully expanded $18 \mathrm{~mm}$ Omnilink stent. The aortic catheter positioned in the descending part of the aortic arch was used as a landmark. (D) Final angiography showing patency of the DA and excluding any site of obstruction.

prenatally in all but three. At the time of admission all were given conventional prostaglandin $\mathrm{E}_{1}$ (PGEl) treatment.

Compassionate treatment, palliative reconstructive surgery, or heart transplantation was offered as a principal treatment option for newborns with hypoplastic left heart syndrome, as is standard in our institution. ' If parents opt for surgical treatment, we accept the family's preference for transplant rather than reconstructive surgery in newborns with hypoplastic left heart syndrome where from the medical point of view either approach is applicable. Continued impairment of right ventricular function, severe tricuspid regurgitation, or coronary fistulae leaves heart transplantation as the treatment of choice. The postnatally performed Norwood l procedure is offered at our institution on an individual basis with preference given to patients with single dominant left ventricular anatomy-for example, double inlet left ventricle, atrioventricular septal defect with right ventricular hypoplasia, and left ventricular-type univentricular heart. Additionally, the combined Norwood 1 and 2 repair, based on the presented combination of interventional and surgical procedures, was applied after principal approval from the institutional review board of the university hospital. Written informed consent was obtained from all parents.

\section{Heart catheterisation}

The technical details of stent implantation have been described previously, ${ }^{6}$ where balloon expandable stainless steel stents (Jo-Med, Ramendingen, Germany; Devon, Hamburg, Germany) were used. These stents were mounted on 4 or 5 French $20 \mathrm{~mm}$ long compliant balloon catheters (Osypka, Rheinfelden, Germany). The hand crimped stents were advanced transvenously over a stiff guidewire (0.018 inch) into the ductus arteriosus, via the pulmonary artery route without guidance of a long sheath. Positioning the stent was guided by landmarks or hand injections of contrast through an aortic catheter placed proximal to the ductus for exact stent deployment. In addition to the previously described technique, we changed to balloon expandable premounted Omnilink stents (Guidant, Isernhagen, Germany) with a length of $18 \mathrm{~mm}$ in the last four procedures. The final diameter of these balloons ranged from $7-7.9 \mathrm{~mm}$ or $9-9.8 \mathrm{~mm}$, respectively, depending on the inflation pressure used. These stents were advanced transvenously over a stiff 


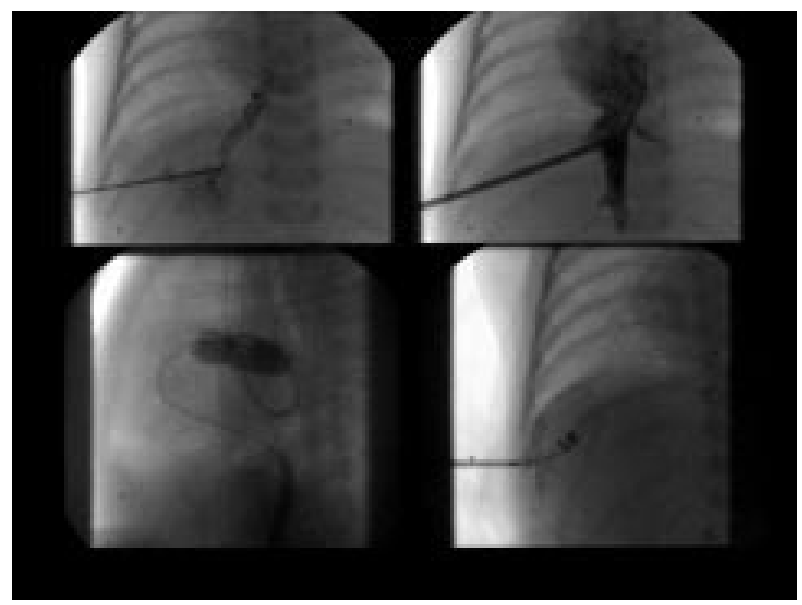

Figure 2 Transhepatic cardiac catheterisation in patient 12 with hypoplastic left heart syndrome. Top left, percutaneous transhepatic puncture with a 22 gauge needle through the interspace-midaxillary line, midway between the diaphragm and lower margin of the liver after local anaesthesia under fluoroscopic guidance and gently infused contrast medium. Top right, 5 French sheath placed into the low right atrium guided by a previously placed wire. Bottom left (lateral view fluoroscopy), inflated balloon catheter placed in the restricted patent foramen ovale necessitates further gradual balloon dilatation. Bottom right, steel coil inserted through the sheath into the liver parenchyma peripheral to the hepatic vein.

guidewire (0.018 inch) through a 5 French sheath (Terumo, Frankfurt, Germany) placed in the pulmonary trunk. Satisfactory stent position in the ductus arteriosus was assessed by angiography (fig 1). PGEl infusion was discontinued following correct stent placement; in five patients PGEl infusion was already stopped almost two hours before heart catheterisation. In five patients two stents $(17 \mathrm{~mm}$ Jo-stent, 13 and $20 \mathrm{~mm}$ Saxx stents, and $18 \mathrm{~mm}$ Omnilink stents, respectively) were used. The second stent was delivered by telescopic placement tailoring the overall stent length to the individual ductal anatomy, in three patients during a second intervention. Gradual balloon dilatation atrial septotomy was performed in patients who did not have unrestricted blood flow through a large atrial septal defect. Balloon catheters with final diameters of 10 or $12 \mathrm{~mm}$ were used. In one, the transhepatic venous cardiac catheterisation procedure as described by Shim and colleagues ${ }^{10}$ was necessary to create an atrial septotomy (fig 2).

\section{Surgical techniques}

In addition to the previously described surgical techniques, ${ }^{6}$ the timing of the bilateral banding of the pulmonary arteries varied from the same day of the catheterisation procedure (two patients), to $1-3$ days afterwards ( 15 patients), to before the intervention with continuous administration of PGEl (three patients). The Dacron mesh material of the banding was held in place by two prolene 6.0 sutures to avoid migration of the banding. Furthermore, in infants with classic hypoplastic left heart syndrome or with aortic atresia, in whom arch reconstruction and BCPC combined in one cardiopulmonary bypass procedure were performed 3.5-6 months later, complete circulatory arrest was avoided by means of cerebral perfusion through innominate artery cannulation. Pump flow was maintained at $90-110 \mathrm{ml} / \mathrm{min}$, despite deep hypothermia. Additionally, the management during weaning and the early post-bypass period was changed by introducing the vasodilatators phentolamine and nitroprusside in our postoperative strategy. In patients with biventricular repair, reconstruction of the interrupted aortic arch was combined with ventricular septal defect repair following bilateral debanding of the pulmonary arteries and removal of the stented ductus arteriosus.

Technical details of transplantation procedure in patients chosen for heart transplantation have been described previously. ${ }^{11}$

\section{RESULTS}

Stenting the duct combined with bilateral pulmonary artery banding in newborns with hypoplastic left heart or multiple left heart obstructive lesions allowed various surgical strategies in 20 patients (fig 3).

In all but two of the 20 patients with various forms of multiple left heart hypoplastic or obstructive lesions, stent implantation in the ductus arteriosus was successful and bilateral pulmonary artery banding effective. Ten patients received palliative surgery with reconstruction of the aortic arch and BCPC in one operation at the age of 3.5-6 months (mean 5.1 months). Two patients had biventricular repair 2-6 months following the initial interventional surgical approach. Two patients underwent heart transplantation 66 and 331 days following ductal stenting and pulmonary artery banding, respectively. Two patients chosen for heart transplantation, one because of postnatal multiorgan failure and one in consequence of an obvious ductal obstruction, died as a result of continued compromised right ventricular function four and three months after the procedure. One patient who is now 8 months old was admitted postnatally with hypoplastic left heart syndrome and since then has been effectively palliated by ductal stent and banding is now planned for biventricular repair. One patient now 2 months old with aortic atresia, hypoplastic aortic arch, and atrioventricular septal defect is scheduled for the presented combined Norwood 1 and 2 repair at the age of 4-6 months.

Table 1 summarises the patients' characteristics at the time of ductal stenting.

Percutaneous procedures were performed with a mean procedural time of 95 minutes and a mean fluoroscopy time of 21 minutes. There was one death: patient 12 (table 1) died minutes after the ductal stent was placed and the interventional

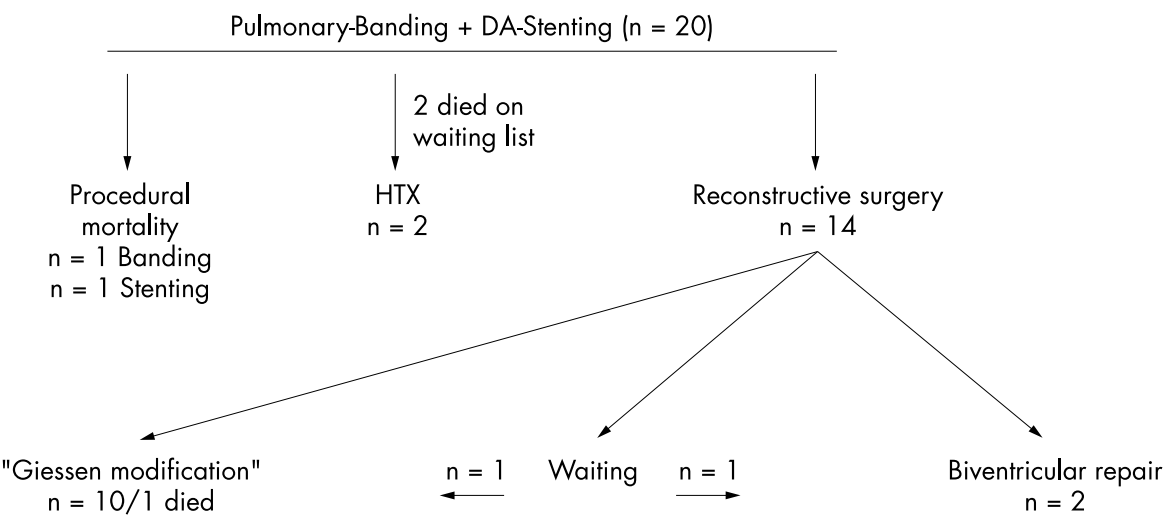

Figure 3 Outcome of 20 patients with various types of hypoplastic left heart obstructive lesions. 


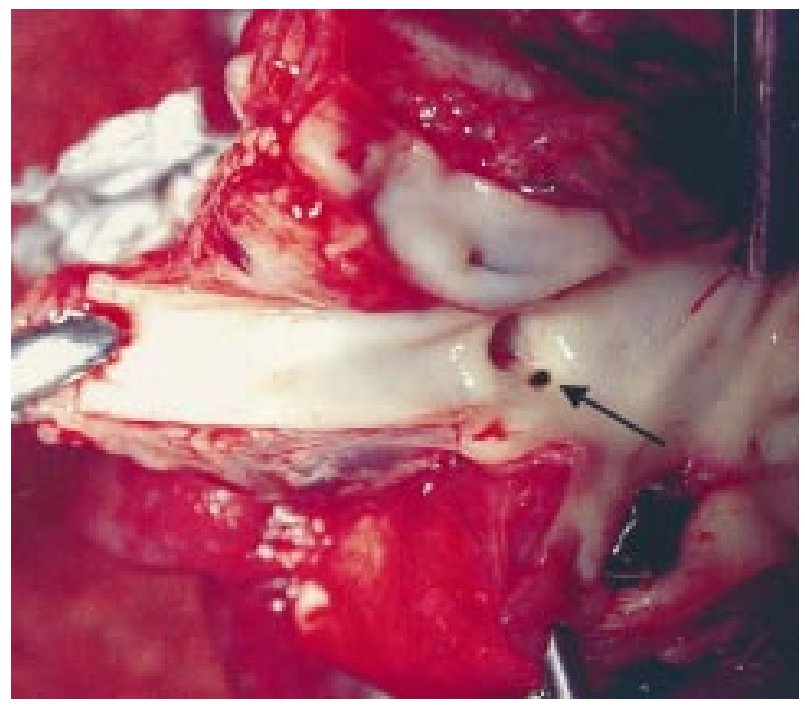

Figure 4 The necropsied specimen. The opened aortic arch shows a diminutive orifice of the ascending aorta at the level of the innominate artery with a diameter of the inner lumen of $<1 \mathrm{~mm}$.

procedure was already finished. Acute ischaemia led to cardiac arrest not responding to medical or mechanical resuscitation, although the stented duct allowed reasonable systolic arterial pressure generation by chest compression. In this premature infant the ascending aorta and root were extremely diminutive, with a diameter $<1 \mathrm{~mm}$ at the site of the innominate artery seen in the necropsy study (fig 4). An obvious mechanical obstruction by the stent or typical coarctation at the descending aortic arch was excluded.

Cardiopulmonary resuscitation was necessary in one further patient. Two patients needed adrenaline (epinephrine) because of transient bradycardia while the stents were advanced through the right heart. Single stent placement was effective in 15 patients. Stent redilatation was necessary in two patients and a second stent was necessary in five patients to cover the ductus arteriosus completely. Stent and ductal patency were achieved for almost one year. The use of premounted stents advanced through a 5 French Terumo sheath increased safety and feasibility of the interventional procedure. The 5 French long sheath induced neither relevant tricuspid valve nor pulmonary valve regurgitation.

Bilateral pulmonary artery banding was accomplished surgically after the transcatheter procedure in 17 patients and before ductal stenting in three patients. The technical details have been described previously. ${ }^{6}$ Two patients needed bilateral banding of the pulmonary arteries immediately because of excessive pulmonary run off, on the same day following the interventional procedures - that is, after atrial septotomy. One patient died a few hours after the surgical bilateral pulmonary banding as a result of stent-duct obstruction that was not immediately recognised. Pulmonary artery branches surgically banded to a diameter of about $2-3 \mathrm{~mm}$ achieved mean pulmonary artery pressures ranging between $12-27 \mathrm{~mm} \mathrm{Hg}$ depending on the actual blood pressure in the pulmonary trunk. In two patients, the banded right pulmonary artery narrowed to less than $2 \mathrm{~mm}$ and was successfully dilated with a $3 \mathrm{~mm}$ balloon catheter. Five patients developed significant cyanosis caused by interatrial flow restriction at the age of 5 weeks to 4 months, which was resolved by repeated balloon dilatation atrial septotomy. In one, the transfemoral venous access was adversely affected after an immediate postnatal Rashkind procedure at 31 weeks' gestation, with a body weight of $1660 \mathrm{~g}$. In this patient aged 2 months with a body weight of $2.1 \mathrm{~kg}$, transhepatic venous cardiac catheterisation was performed twice within eight days to achieve a widely patent atrial septum defect (fig 2).
Two patients aged 3 and 5 months developed low cardiac output at home because of a stenosis at the aortic part of the ductus arteriosus, which was not fully covered by the implanted stent. Emergency balloon dilatation was performed but both patients continued to have right heart failure. One of them finally died waiting for a donor heart. The parents of the other one refused heart transplantation for religious reasons, so reconstructive surgery was performed as a rescue approach. This infant died of postoperative right heart failure.

Surgical removal of the ductal stent was uneventful in all patients, but one developed transient diaphragmatic paralysis. As described before, ${ }^{6}$ reconstruction of the aortic arch by placement of an allograft tube was associated with significant postoperative sequelae such as significant stenosis of the left pulmonary artery and distal aortic arch obstruction. Stenosis at both sides was effectively managed by balloon dilatation and stent placement, respectively. Extended augmentation of the aortic arch avoided neoaortic arch obstruction in the last six of our patients. The BCPC performed at the site of the previous right pulmonary artery banding was uneventful in all but one. In one patient the narrowed cavopulmonary connection was stented and venovenous collaterals were embolised by metallic coils (Cook, Bloomington, Indiana, USA) for treatment of significant postoperative oxygen desaturation. No patient had pleural effusions or excessive chest tube drainage for more than five days after surgery. Postoperative oxygenation with a mean arterial oxygen saturation of $65 \%$ on arrival at the intensive care unit improved over the first 48 hours to $75-85 \%$ at time of hospital discharge. In the postoperative period haemodynamic stability was secured mainly by vasodilatation of the pulmonary vascular bed and systemic arteries.

The overall survival rate of all patients with ductal stenting combined with bilateral pulmonary banding is now $75 \%$. The presented surgical modification in hypoplastic left heart lesions has been performed with a success rate of $90 \%$. In clinical follow up of one month to three years only one patient, who was postnatally in severe cardiogenic shock, developed major neurological complications. One patient is awaiting total cavopulmonary connection. In the same period at our institution 10 patients with left heart obstructive lesions underwent the classic Norwood l operation, four died in the early postoperative period, and another received a donor heart four weeks after the Norwood 1 operation. During the review process of our article, one patient (patient 20 in table 1) underwent biventricular repair and the patient awaiting total cavopulmonary connection has meanwhile undergone a successsful operation.

\section{DISCUSSION}

Stenting of the arterial duct combined with bilateral pulmonary artery banding in newborns with hypoplastic left heart or multiple left heart obstructive lesions allows a variety of surgical strategies. Recently, we described this interventional surgical procedure as a basis for a modified surgical technique - that is, neoaortic reconstruction, part of first stage of palliation of hypoplastic left heart, together with BCPC in a single operation with cardiopulmonary bypass beyond the neonatal period, as well as heart transplantation after an extended waiting period. ${ }^{6}$ Additionally, this still preliminary experience in a series of 20 patients shows that the approach of ductal stenting and bilateral pulmonary banding provides the opportunity not only for a combined first and second stage procedure or for delayed heart transplantation but also for biventricular repair in newborns with multiple left heart obstructive lesions. In this context, an additional advantage of the presented strategy seems to be relevant in patients with various left heart hypoplastic or obstructive lesions suffering postnatal cardiogenic shock or in whom additional reasonable non-cardiac problems, as described under Methods, are 
present. The potential of complete recovery of heart function, multiorgan failure, and neurological complications is the clue for better long term outcome regardless of the cardiac surgery. The established treatment strategies do not give the opportunity of waiting until a prospective decision can be made. Even patients with multiple left heart obstructive lesions, in whom the immediate postnatal decision regarding single ventricle palliation or biventricular approach is unclear, may benefit from the presented strategy. The controversy regarding whether the presence of antegrade flow in the ascending aorta is predictive of a successful biventricular approach, as shown in one series ${ }^{12}$ but not supported by another, ${ }^{13}$ highlights additionally the importance of selecting the appropriate strategy in early infancy. The interventional surgical approach presented here may be considered in postnatal decision making of borderline left heart obstructive lesions.

On the basis of a critical analysis of the 20 patients and our recently published data ${ }^{6}$ we offer the following recommendations regarding interventional and surgical techniques and strategy.

\section{Considerations regarding cardiac catheterisation and stent placement}

Firstly, a newborn with a hypoplastic left heart lesion admitted with PGEl infusion with a wide open duct with no detectable ductal narrowing and unrestricted interatrial communication would be considered for bilateral banding within the first 3-5 postnatal days or earlier, if a pulmonary run off in consequence of a postnatal decrease in pulmonary vascular resistance is observed. Ductal stenting, as we described recently, ${ }^{6}$ as well as re-evaluation of the effectiveness of the bilateral banding, would be performed 2-3 days before the patient should be discharged home. In such a case, we would discontinue the PGEl infusion 2-3 hours before catheterisation to achieve a smaller and narrowed duct, facilitating stent placement and preventing stent dislocation.

A newborn with a restrictive patent foramen ovale (mean gradient $>5 \mathrm{~mm} \mathrm{Hg}$ ) would be catheterised before bilateral banding is provided. In case of an already recognisable narrowing at any part within the duct, even if no pressure gradient is detectable, a stent would be placed immediately before the patent foramen ovale is dilated. Effective patent foramen ovale dilatation can be achieved with a balloon diameter of $10-12 \mathrm{~mm}$. If the femoral vein is not accessible for cardiac catheterisation, the percutaneous transhepatic venous approach is feasible especially in a premature infants.

Any haemodynamically relevant ductal stenosis, particularly in patients with cardiogenic shock, and ineffective pharmacological treatment are, in our view, indications for balloon dilatation or stent implantation in the arterial duct, and also as a rescue procedure.

Secondly, the technical aspects of ductal stenting have changed over time, not least with respect to improved stent design. We started with the technique as described by Gibbs and colleagues, ${ }^{514}$ followed by the technique described previously. ${ }^{6}$ We also used for the first time premounted stents with balloon diameters useful for ductal stenting in patients with duct dependent systemic blood flow. These stents can be advanced through a $25 \mathrm{~mm}$ long 5 French Terumo sheath, which can easily be placed in the pulmonary trunk without any haemodynamic compromise, as we have seen using 7 French sheaths as described by Gibbs and colleagues. ${ }^{5}$ Additionally, the premounted stents have a low profile, which makes them very flexible and allows multiple repositioning manoeuvres contributing to a safer procedure. Therefore, we would recommend the stent design and implantation procedure described here, particularly when starting with ductal stenting.

\section{Considerations regarding the surgical techniques}

Firstly, bilateral pulmonary artery banding is principally easy with the technique we described previously. ${ }^{6}$ We experienced narrowing of the duct and displacement of the stent during the banding operation in one patient, who died a few hours after the easily performed bilateral banding led to the following change of strategy. Pulmonary artery banding was performed in all patients with a wide open duct before the ductal stent was placed. In cases where the catheterisation has to be performed first, the surgeon has to be very careful to avoid stent obstruction or displacement. Too much traction while the band is being placed and secured to the adventitia of the pulmonary artery branch or uncontrolled impingement of the stented duct may result in deleterious restriction of ductal flow to the coronary arteries or the descending aorta.

Secondly, extended augmentation of the aortic arch and patch augmentation of the pulmonary arteries just proximal to the left bifurcation may solve the problem of coarctation on both sides. ${ }^{6}$ Additionally, avoiding complete circulatory arrest by means of cerebral perfusion through the innominate artery and introducing the arterial and venous vasodilatators phentolamine and nitroprusside, respectively, during weaning, as well as intensive care management, may be why in individual cases no further inotropic support is necessary other than the already routinely used phosphodiesterase inhibitor milrinone.

However, the long term implication of the described approach has to be elucidated in further studies. A significant number of patients who are not yet suitable for reconstructive surgery and whose parents opt for transplantation die awaiting a donor heart because of heart failure or increasing pulmonary artery resistance. In principle stent implantation in the ductus arteriosus provides the possibility of long term ductal patency. At the same time, protection of the lung vasculature from high pressure by bilateral pulmonary artery banding with low resistance enables transplantation as long as 11 months later. But close follow up is necessary to detect restrictive interatrial communication, narrowing of the duct, or compromised pulmonary blood flow before heart function worsens. In addition, the development of significant aortic coarctation with compromised retrograde blood flow and coronary perfusion at risk must be diagnosed very early. Altogether, maintenance of ductal patency by stent implantation is attractive but in practice the quality of palliation requires much experience in interventional paediatric cardiology, as well as experience in the echocardiographic and clinical assessment of the haemodynamics in follow up before further surgery is undertaken.

\section{Conclusion}

Stenting of the arterial duct and banding of the pulmonary arteries expand the possible surgical strategies in newborns with multiple left heart obstructive lesions. In particular, moderate hypoplasia of the left ventricle or left sided valves may mature with time and allow biventricular repair after some months. For these patients the presented approach is a "bridging procedure". The same is true for newborns with associated non-cardiac disorders with significant relevance concerning total outcome, where the decision regarding definitive cardiac repair can be postponed.

However, with respect to the deaths on our heart transplantation waiting list, one of our goals is to evaluate the combined interventional and surgical approach as a bridging procedure for transplantation as well. Regarding the experience with the Norwood procedure without circulatory arrest, as described by Imoto and colleagues, ${ }^{15}$ we hypothesise that cardiopulmonary bypass, which also allows complete avoidance of circulatory arrest and deep hypothermia in the combined Norwood 1 and 2 repair, may also enable this surgical technique to be used as a bridging method. In this context, the early use of BCPC with relief of volume load for a weak single right ventricle by establishing serial instead of parallel pulmonary and systemic circulations may support this strategy. Changes in surgical techniques, as well as in perioperative management, imply a 
learning curve for the whole team. Improvement has been achieved and can be expected in the future.

\section{Authors' affiliations}

I Michel-Behnke, H Akintuerk, I Marquardt, M Mueller, J Thul, J Baver, K J Hagel, J Kreuder, P Vogt, D Schranz, Paediatric Heart Centre, Justus-Liebig University Giessen, Giessen, Germany

\section{REFERENCES}

1 Baver J, Thul J, Krämer U, et al. Heart transplantation in children and infants: short- term outcome and long-term follow-up. Pediatr Transplant 2001;5:457-62.

2 Ishino K, Stümper O, De Giovanni JV, et al. The modified Norwood procedure for hypoplastic left heart syndrome: early to intermediate results of 120 patients with particular reference to aortic arch repair. J Thorac Cardiovasc Surg 1999;1 17:920-30

3 Thies WR, Breymann T, Cherlet $E$, et al. Anatomical and functional hypoplastic left heart syndrome and its surgical therapy by Norwood and Fontan operation. Z Kardiol 1997:86:505-13.

4 Mahle WT, Spray TL, Gaynor JW, et al. Unexpected death after reconstructive surgery for hypoplastic left heart syndrome. Ann Thorac Surg 2001;71:61-5.

5 Gibbs JL, Wren C, Watterson KG, et al. Stenting of the arterial duct combined with banding of the pulmonary arteries and atrial septectomy or septostomy: a new approach to palliation for the hypoplastic left heart syndrome. Br Heart J 1993;69:551-5.
6 Akintürk H, Michel-Behnke I, Valeske K, et al. Stenting of the arterial duct and banding of the pulmonary arteries: basis for combined Norwood stage I and II repair in hypoplastic left heart. Circulation 2002; 105: 1099-103.

7 Alboliras ET, Mavroudis C, Pahl E, et al. Left ventricular growth in selected hypoplastic left ventricles: outcome after repair of coarctation of the aorta. Ann Thorac Surg 1999;68:549-55.

8 deLeval MR. The Fontan circulation: what have we learned? What to expect? Pediatr Cardiol 1998;9:316-20.

9 Hehrlein FW, Yamamoto T, Orime Y, et al. Hypoplastic left heart syndrome: which is the best operative strategy. Ann Thorac Cardiovasc Surg 1998;4:125-32

10 Shim D, Lloyd TR, Cho KJ, et al. Transhepatic cardiac catheterization in children: evaluation of efficacy and safety. Circulation 1995:92:1526-30.

11 Dapper F, Baver J, Kroll J, et al. Clinical experience with heart transplantation in infants. Eur J Cardiothorac Surg 1998;14:1-5.

12 Tchervenkov $\mathrm{Cl}$, Tahta SA, Jutras LC, et al. Biventricular repair in neonates with hypoplastic left heart complex. Ann Thorac Surg 1998;66:1350-7

13 Schwartz M, Gauvreau K, Geva T. Predictors of outcome of biventricular repair in infants with multiple left heart obstructive lesions. Circulation $2001 ; 104: 682-7$

14 Gibbs JL, Uzun O, Blackburn MEC, et al. Fate of the stented arterial duct. Circulation 1999;99:2621-5.

15 Imoto Y, Kado H, Shiokawa Y, et al. Experience with the Norwood procedure without circulatory arrest. J Thorac Cardiovasc Surg $2001 ; 122: 879-82$.

\section{IMAGES IN CARDIOLOGY}

\section{Thirty years after percutaneous closure of patent ductus arteriosus*}

A 68 year old woman presented with new onset of dyspnoea and fatigue. Thirty years previously she was diagnosed as having a patent ductus arteriosus. At that time the left-to-right shunt across the patent ductus was found to be $33 \%$, and no evidence of pulmonary vascular disease was present. A transcatheter closure of the patent ductus arteriosus was performed percutaneously using an Ivalon plug with a metallic skeleton as occluder device (Porstmann and Wierny: Z Gesamte Inn Med, 1968).

Thirty years later the patients lung and renal function were well preserved; the ECG and laboratory values did not show any abnormalities and could not help elucidate the patient's symptoms. Transthoracic echocardiography showed normal systolic function but reduced early transmitral velocity compared with increased atrial velocity and shortened deceleration time.

However, multiplane transoesophageal echocardiography (panel A) demonstrated the correct position of the Ivalon occluder (size $11 \times 13 \times 8 \mathrm{~mm})$ (arrow).

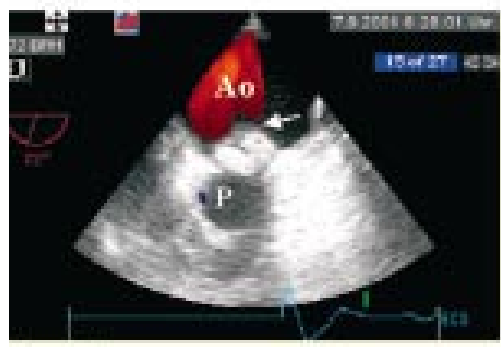

Panel A

Between the pulmonary trunk $(\mathrm{P})$ and the proximal descending aorta (Ao) just distal to the left subclavian artery, the smooth wrapping (envelope) of the Ivalon plug is seen. A left-to-right shunt was excluded. The diastolic dysfunction was confirmed with left and right heart catheterisation. The angiogram of the aorta (panel B) demonstrates the metal nucleus (skeleton) of the occluder device (arrow). There was no evidence of coronary artery disease, valvar heart disease, left-to-right or right-to-left shunt

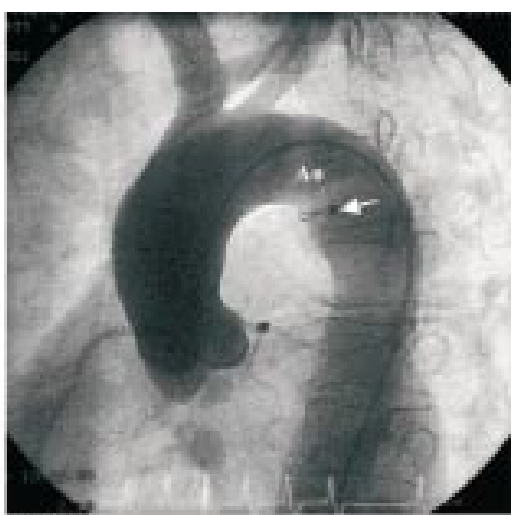

Panel B

with correct position of the ductus occluder more than three decades after percutaneous placement.

\section{A C Borges \\ V Gliech \\ G Baumann \\ adrian.borges@charite.de}

* In memorial of Professor Werner Porstmann (19211982), who introduced this method and was the first to perform this procedure at the Charité University Hospital Berlin in 1966 